\title{
Mobiliario y pintura en las casas de los marqueses de Santa Cruz de Marcenado (Asturias) entre los siglos XVII y XVIII
}

\author{
Furniture and paintings in the houses of the \\ marqueses de Santa Cruz de Marcenado (Asturias) \\ between the $17^{\text {th }}$ and $18^{\text {th }}$ centuries
}

\author{
Luis Ramón-Laca Menéndez de Luarca \\ Universidad de Alcalá
}

\section{RESUMEN}

A través de documentos inéditos de archivo, se analizan y estudian en detalle los conjuntos de muebles y la colección de pintura que quedaron a la muerte de don Sebastián Vigil de Quiñones y la Rúa y de su hija Jacinta, en sus casas de la villa de Pola de Siero y Oviedo (Asturias). Tanto los muebles como los cuadros se destruyeron o quizá dispersaron durante la Guerra de Independencia, cuando la Casa de la Rúa de Oviedo fue saqueada en reiteradas ocasiones. No obstante, los inventarios transcritos en este artículo ilustran perfectamente la riqueza de la que hacía gala en Asturias la nobleza de la época, como se comprueba comparando los inventarios estudiados con los de otras familias emparentadas con los Vigil de Quiñones, por ejemplo los Miranda, marqueses de Valdecarzana.

Palabras clave: Mobiliario, Inventarios, Colección de pintura, Nobleza, Siglos XVII y XVIII, Asturias.

\section{SUMMARY}

Using unpublished archival documents, the author studies and analyses in detail the collections of furniture and paintings left at the time of their deaths by Sebastian Vigil de Quiñones y la Rúa and his daughter Jacinta in their houses in the town of Pola de Siero and the capital, Oviedo (Asturias). Both furniture and paintings were destroyed - or perhaps dispersed- during the Napoleonic Wars, when la Rúa's house in Oviedo was repeatedly sacked. Nevertheless, the inventories here transcribed perfectly demonstrate the wealth displayed by the Asturian nobility of the period, which can be verified by comparing these inventories with those of other families related to the Vigil de Quiñones, for example the Miranda, marqueses de Valdecarzana.

Key words: Furniture, Inventories, Painting Collection, Nobility, $17^{\text {th }} \& 18^{\text {th }}$ Centuries, Asturias. 


\section{INTRODUCCIÓN}

Los inventarios post-mortem se han utilizado frecuentemente como fuente básica para el conocimiento de las mentalidades y la cultura material de las sociedades en diferentes épocas y lugares (Bennassar 1982). El hecho de que en España se haya conservado un enorme número de protocolos notariales ha permitido reconstruir a la perfección (basándose casi exclusivamente en este tipo de documentos), por ejemplo, el coleccionismo de pintura en el Madrid del Siglo de Oro (Burke y Cherry 1997). Como señalan Burke y Cherry (1997: XIII), aquella época fue testigo de una moda, casi una manía, el coleccionismo de obras de arte (sobre todo pintura), que afectó en el momento a una variada gama de españoles, desde el Rey, sus nobles y sus ministros hasta individuos relativamente humildes que vivían en Madrid.

En este caso, analizaremos los inventarios post-mortem de un padre y una hija, don Sebastián y doña Jacinta Vigil de Quiñones, I Marqués y II Marquesa de Santa Cruz de Marcenado; el primero de su Casa del Jardín de Pola de Siero y el segundo de la Casa de la Rúa de Oviedo, ambos referentes a Asturias.

Como suele ser habitual en este tipo de documentos, no se hace referencia a la situación concreta de las pinturas o los muebles, mezclándose unas con otros, ya que los inventarios se realizaban de corrido, habitación por habitación. En el caso del inventario de los bienes que quedaron a la muerte del I Marqués, el documento, fechado en 1692, ofrece pocos detalles sobre la Casa del Jardín; por el contrario, en el de su hija, de 1717, sí aparecen mencionadas las diferentes habitaciones de la Casa de la Rúa, lo que permite imaginar el ambiente interior de dicha casa a principios del siglo XVIII.

Es sabido que este tipo de inventarios se llevaban a cabo tras la muerte de los poseedores de los bienes: en el primer caso, para llevar a cabo las particiones correspondientes a los hijos de don Sebastián, fruto de dos matrimonios, de los bienes (procedentes de Madrid) aportados al matrimonio por su segunda mujer, doña María Josefa de Ribas Guerra; en el caso de doña Jacinta Antonia, el inventario se llevó a cabo seguramente por cuestiones relacionadas con la testamentaría correspondiente, aunque en ese caso los hijos de la II Marquesa eran fruto de un único matrimonio, con don Juan Antonio Navia-Osorio. Como es habitual, el inventario de los bienes tras la muerte de don Sebastián lo llevaron a cabo los miembros de la familia, asistidos por el escribano de Siero, Andrés Vigil Bernardo. En ausencia de parientes, en el caso del inventario de doña Jacinta, lo llevó a cabo don Juan Bautista Burgalés de Aguilar, gobernador político y militar de Oviedo y del Principado de Asturias; el primogénito, don Álvaro Navia-Osorio se encon- 
traba en aquel momento en el Puerto de Santa María (Cádiz), al frente de los ejércitos del rey Felipe V.

\section{LOS PROPIETARIOS}

\section{Don Sebastián Vigil de Quiñones y la Rúa}

Don Sebastián Vigil de Quiñones y la Rúa nació en el concejo de Siero y fue bautizado en la parroquia de Santa María de Moldano (Lieres, Asturias) el 20 de enero de 1638 (Calatrava 2795). En el expediente para la concesión del hábito de Calatrava, fechado en 1669, se afirma que "dicho Don Sebastián Bijil se alla dueño de casas de conocida nobleça y renta en Asturias, y con serbicios y puestos honoríficos sus ascendientes". Sus padres fueron Bernabé de Vigil, del concejo de Siero, y Antonia de la Concha, de la ciudad de Oviedo; sus abuelos paternos, Bernabé Vigil, también del concejo de Siero, e Isabel de la Rúa, natural de Oviedo, y los maternos, Diego de la Concha, natural del valle de Carriedo e Isabel de Cifuentes, de la ciudad de Oviedo (Abol 1986). En 1679 se le concedió el título de Marqués de Santa Cruz de Marcenado por Real Despacho (de 28 de agosto). Don Sebastián se casó dos veces, la primera con doña Isabel Bernardo de la Rúa y Valdés, madre de doña Jacinta Antonia y doña María Teresa, y la segunda con doña María Josefa de Ribas (o Rivas) Guerra, madre de doña Rosa Gertrudis y doña María Josefa. La segunda mujer del I Marqués, a juzgar por los bienes que aportó al matrimonio, fue una mujer rica. María Josefa era hija de Vicente de Ribas, quizá un Vicente de Rivas, director de la Compañía de Caracas, de Madrid, que aparece como testigo en 1680 en el expediente para la concesión del hábito de Alcántara a don Joaquín Zapata y Mendoza (Cadenas y Vicent 1991: 105).

\section{Doña Jacinta Vigil de Quiñones y Bernardo de la Rúa}

Su hija Jacinta Vigil de Quiñones y Bernardo de la Rúa, fruto del primer matrimonio de don Sebastián (con doña Isabel Bernardo de la Rúa y Valdés), heredó el título a la muerte de su padre, acaecida en 1692. Doña Jacinta contrajo matrimonio con don Juan Antonio Navia-Osorio, del que tuvieron tres hijos: Álvaro, Bernarda y Josefa, la última muerta antes que su madre. La II Marquesa murió el 10 de julio de 1717 en la Casa de la Rúa de Oviedo, habiendo testado un mes antes:

[...] este que hago y otorgo zerrado y sellado ante el presente escribano, y firmado de mi nombre en las mismas casas de la Rúa, a seys días del mes de junio 
de mil setecientos y diez y siete años. [...] doña Jazinta Antonia Vigil de la Rúa, Marquesa de Santa Cruz de Marcenado, viuda del señor don Juan Antonio Navia y Osorio [...]. Conoziéndome mortal y temiendo de la ora, por achaques en que muchos días me hallo, deseando morir en grazia de Dios [... ] es mi voluntad [que mi cuerpo] sea sepultado en la yglesia del convento de Nuestro Seráfico Padre San Francisco, extra muros de dicha ciudad, y en el sepulcro que en dicha yglesia tiene la mi Casa de la Rúa.

[...] Y también digo tengo por mis hijos lexítimos y de el dicho don Juan Antonio Navia y Osorio, mi marido, a Don Alvaro de Navia Osorio, vizconde de Puerto, coronel de ynfantería española, brigadier de los ejérzitos de Su Magestad, Ynspector Jeneral de las Armas de Andalucía y costa de Granada, residente al presente en la gran çiudad y Puerto de Santa María, [...a] doña Bernarda de Navia Osorio [...y a] doña Josepha Navia Osorio (difunta).

[...] Y también es mi voluntad que si yo falleciese antes que llegue a esta çiudad el Vizconde mi hijo, los que lo son suios y duplicados míos, don Juan Alonso y doña Jazinta Navia y Osorio mis dos amados nietos, a quienes siempre e tenido en mi compañía, con el amor y cariño de duplicada madre, se mantengan en estas dichas mis casas de la Rúa con los mismos criados y asistenzia que e tenido y tengo asta que el dicho su padre y mi hijo llegue y disponga [...] (AHPA 1717 bis).

Llama la atención el hecho de que doña Jacinta mencione en su testamento una suma de dinero que su padre había malgastado y que debía haberse empleado en la fundación de una capellanía:

[...] y también declaro que haviendo benido a poder de D. Bernabé Vigil quatro mill y tantos ducados de los Reinos de Indias para fundar una capellanía, adbocazion de Santa Polonia sita en la parrochial de San Phelix de Baldesoto y no lo aver echo a causa de aberse muerto, y aber pasado dicho caudal con poder del Señor Don Sevastián de Vigil mi padre, y abérsele consumido su señoría, por cuia causa para fundar dicha capellanía en lugar de dicho caudal consigno ochenta fanegas de pan sitas en el qoncejo de Bimenes (AHPA 1717 bis).

\section{LAS CASAS}

\section{La Casa del Jardín de Pola de Siero}

La Casa del Jardín se construyó formando parte, sin duda, del mismo proceso de enaltecimiento que don Sebastián desplegó a lo largo de su vida, incluyendo la concesión del hábito de Calatrava en 1669 y del título de marqués en 1679, así como su política matrimonial. En efecto, don Sebastián se casó dos veces, y las dos con mujeres ricas, primero con una representante de la hidalguía de Oviedo y después con una mujer procedente de Madrid que aportó al matrimonio una importante dote (Díaz Álvarez 2002; Díaz Álvarez 2006). En este contexto, tiene todo el sentido la construcción 
de una nueva residencia en las afueras de Pola de Siero, en la que poder albergar la extensa colección de enseres, muebles y pintura que el I Marqués había llegado a acumular. Hasta entonces, los Vigil de Quiñones habían vivido en sus casas principales de Pola de Siero:

[...] las casas principales en que vive en esta villa dicho señor don Sebastián Vigil con sus entradas y salidas y dos orrios de seis pies tras dichas casas con sus suelos y corradas de entre medias de dichas casas y de dichos orrios según que por la parte hacias las campas lindan dichos vienes con árboles de la casa de Zelles y con otra casa de este apeo y huerto que está pegado a ella, y de la parte de hacia arriva con una calle fuera de entre dichas casas y casa de don diego de Argüelles y de la parte de abajo con una plazuela que pega con el río, según dichas casas tienen un pasadizo desde ella a la capilla de Santa Catalina de la yglesia de esta villa [...] (Díaz Álvarez 2007: 202, n. 8).

La Casa del Jardín se conserva hoy parcialmente, transformada en casa de cultura. En origen, es posible que su planta fuera cuadrada, alrededor de un patio cuadrado, con torres en las esquinas; hoy presenta forma de U. Es propiedad del Ayuntamiento de Siero, que lo compró a los descendientes del I Marqués en 1993 (información del Catálogo Urbanístico de Siero). Tenía unos jardines importantes, hoy transformados en el llamado Parque de Alfonso x, que estaban rodeados por un muro, hoy desaparecido.

En el inventario de bienes que quedaron del Marqués, realizado en la villa de Siero el 19 de enero de 1692 en su casa de la villa, se mencionan, entre otros bienes, una colección de pintura formada por 44 cuadros, más dos espejos grandes y dos pequeños, varias mesas (entre ella tres de seis patas, una de cinco patas, otra "de encaje" de tres piezas y otra de cuatro pies embutida), una mesa de billar ("de trucos con sus bolas y tacos"), sillas "de baqueta de moscobia", bancos (entre ellos "un bancón de nueve a diez varas de largo y media de ancho") una silla de manos, tres bufetes (entre ellos uno de cuatro patas), dos escritorios de granadillo, un escaparate, varios baúles, arcas y varias camas (entre ellas una de madera tallada, la cama del Marqués, otra blanca dorada con dosel, otra de ébano con colgaduras de damasco encarnado guarnecido de seda y otra encarnada con colgaduras, dosel y guarnición de damasco verde), arcas y baúles y una alfombra turca (ACHV 1692, doc. 1).

La colección de pintura, en su mayor parte formada por obras aportadas al matrimonio por doña María Josefa Ribas Guerra, incluía 55 cuadros: cuatro Ángel de la Guarda (uno algo dorado y otro con letrera), una Virgen de las Angustias, un cirujano con jeringa, tres cristos (uno con San Francisco y otro "enarbolado en la cruz"), un David, una Encarnación, dos espejos grandes y dos pequeños dorados, tres fruteros (uno viejo), unas lágrimas de San Pedro de gran tamaño ("algo dorado"), un león, un lobo, 
tres magdalenas (una convertida y otra difunta), un retrato del I Marqués, un San Antonio, un San Diego de Alcalá, un San Fernando con las llaves de Sevilla, dos San Francisco (uno ya viejo y otro de la tentación), un San Ignacio, un San Jerónimo, un San José, dos San Juan (uno con el cordero), un San Lorenzo (pequeño de marco dorado), un San Pablo, dos San Pedro (uno con sus llaves), dos San Sebastián, una Santa Catalina, una Santa Clara (sin marco), una Santa Isabel Reina de Portugal, una Santa Marina, una Santa Rosa de Viterbo, una Santa Rosa del Perú, un Santo Domingo con otras imágenes, un Santo Domingo soriano, dos tigres, varias vírgenes (entre ella Nuestra Señora de la Asunción, Nuestra Señora de la Concepción, Nuestra Señora de la Encarnación con marco dorado, Nuestra señora de la Soledad, Nuestra Señora de los Siete Dolores, una Virgen del Rosario pequeña y una Virgen en contemplación grande).

Entre los muebles, llama la atención la "mesa de trucos con sus bolas y tacos", el "bancón de nueve a diez varas de largo y media de ancho" (unos 8 metros) la silla de manos, los escritorios de granadillo, el "escaparate grande nuevo con las armas de la casa de Vigil para la plata y los vidrios con su escalera" que estaba en el cuarto "de las chimineas", el "baúl de granadillo con listas blancas", la cama del Marqués (de ébano con barandillas) y varias camas con dosel (una blanca dorada) y colgaduras (una de ébano y damasco encarnado y otra de damasco verde), la alfombra turca y una piel de oso.

\section{La Casa de la Rúa a comienzos del siglo XVIII}

La Casa de la Rúa, que pasó a los marqueses de Santa Cruz de Marcenado por el matrimonio en 1655 de doña Isabel Bernardo de la Rua con don Sebastián Vigil de Quiñones, está situada en la calle de la Rúa de Oviedo. Hasta la década de los treinta del siglo Xx, su fachada daba frente a la calle de Platerías, que tras el derribo de una manzana completa se incluyó en la plaza de la Catedral que hoy conocemos (plaza de Alfonso II el Casto) (Ramón-Laca y Ríos 2008). La Casa se levanta sobre un solar de estructura típicamente medieval, estrecho y largo, con una superficie de unos 1.250 metros cuadrados, de los que el edificio en sí ocupa unos 645 metros cuadrados en planta baja, 550 en la segunda, 500 en la tercera y 275 en la cuarta. El resto de la parcela, situada tras el edificio — hacia el oeste-, está ocupada por un jardín.

La Casa que ha llegado hasta nosotros corresponde principalmente a la reforma llevada a cabo entre 1928 y 1929 según el proyecto del arquitecto madrileño Miguel Ángel García Lomas. Aunque se considera generalmente 
la casa más antigua de la ciudad, de la primitiva construcción, realizada posiblemente a finales del siglo XV o principios del XVI, únicamente queda la fachada principal y el siguiente muro paralelo a ésta en las dos primeras plantas. En el siglo XVIII, se adosó a la fachada medieval un cuerpo de tres pisos de altura, obra probable del arquitecto asturiano Manuel Reguera. Diversos autores han venido sosteniendo que esta es la única casa existente en la actualidad que se salvó del incendio de Oviedo, ocurrido en la noche de Nochebuena de 1521. Sin embargo, los trabajos de restauración de la Casa dirigidos por el autor de este trabajo durante los últimos años han demostrado que el incendio de Oviedo afectó gravemente a la casa, a consecuencia del cual se llevaron a cabo una serie de intervenciones durante los siglos XVI y XVII.

El interior de la casa correspondiente a aquella época aparece descrito en el inventario realizado en 1717 tras la muerte de la II Marquesa (AHPA 1717 bis, doc. 2). Para llevar a cabo el inventario, el recorrido fue el siguiente: (se refieren seguramente a la planta alta), comenzaron por una "antesala que cae a la calle pública", de allí pasaron "al otro cuarto de estrado que sigue a dicha antesala y cae a la calle", de allí "al pasadizo y primer quarto de él correspondiente a dicho estrado", de allí "al segundo quarto del mismo pasadizo", de allí "al quarto del estrado que cae al jardín", de allí "al dormitorio que corresponde a dicho quarto de estrado, que es él en donde fallezió la dicha Marquesa", de allí "a la sala grande que cae al Jardín", de allí "a la antesala de la sala referida", de allí "al cuarto del corredor que está a espaldas de la sala y que corresponde al patio de dichas casas", de allí "a otros dos quartos nuebos que corresponden al mismo patio" (hasta aquí la planta alta), de allí "al quarto que llaman de sorriba", de allí "al pasadizo de él que se halla junto a la escalera de la torre", de allí "al quarto grande de la cozina y un dormitorio", de allí "al corredor que corresponde al jardín" y finalmente de allí "al oratorio que se halla a un lado del mismo corredor".

La colección de pintura estaba formada por siete cuadros grandes de santas y virtudes, tres cuadros viejos pequeños, tres paisajes ("países") largos con marcos dorados, tres cuadros grandes de pintura fina, un cuadrito pequeño viejo, cuatro pinturas grandes antiguas, cinco cuadros pequeños, nueve cuadros grandes sin marcos, un cuadro pequeño y viejo, más una efigie del Santo Cristo de plata y un San Sebastián (además de láminas, un misal y ornamentos) que había en el oratorio, lo que hace un total de 37 pinturas (más una imagen).

Entre los muebles, se encontraron tres mesas de madera (dos de seis y una de cuatro pies y una mesa grande con dos tiradores), seis bancos de respaldo (cuatro de ellos torneados), doce sillas y un taburete de vaqueta 
de Moscovia, seis escritorios (dos de ellos de tortuga finos con sus mesillas, uno de madera negro sin mesilla, uno antiguo viejo de madera, otro viejo de tortuga y otro grande de madera), tres mesillas, un Niño Jesús en un escaparate con vidriera, una estera fina de ochos clavada en la pared, almohadas de damasco encarnado y de damasco negro de estrado, una mesa de nogal embutido de estrado, cuatro cortinas de morlés en puertas y ventanas, tres cortinas de damasco encarnadas y tres de tafetán verde, cuatro cortinas de estameña verdes, arcas (una en el dormitorio de la II Marquesa que contenía 18 bollos de libra chocolate) y baúles, una arqueta pequeña y larga, varias camas (tres de nogal, una de ellas de campo de nogal embutida, una de madera vieja, una de granadillo bronceada con colgadura de damasco de seda encarnada [seguramente la citada en Pola de Siero], una de granadillo, otras de madera ordinarias, una de madera encarnada con colgadura de damasco verde y rodapiés de lo mismo [seguramente la citada en Pola de Siero]), dos espejos grandes de vestir, un brasero bronceado, un biombo viejo, un cajón de madera en el que estaba el servicio de mesa, es decir, la plata (un taller, una salvilla, una fuente, un jarro, una palangana, un bernegal, cuatro vasos, ocho tenedores, once cucharas, cuatro candeleros, cuatro tenedores, un cáliz y una patena) y el menaje de cocina (tres herradas, siete calderas, un almirez con mano, un pote de hierro, cazos, dos asadores, dos chocolateras, cinco docenas de platos de peltre y seis fuentes de peltre).

Además, entre los bienes se incluyen un furgón con dos mulas y una esclava negra que se llamaba Teresa de Jesús.

\section{CONCLUSIONES}

Aunque la colección de pintura descrita en el inventario de la Casa del Jardín correspondía en su mayoría a bienes privativos de doña María Josefa Ribas, es posible que algún cuadro pasara a la Casa de la Rúa, ya que las cifras tienen alguna relación: 55 obras en Siero y 38 en Oviedo. Asimismo, otros enseres acabaron en la Casa de la Rúa, lo que al final significó su destrucción, por ejemplo las "sillas de baqueta de Moscovia" que aparecen citadas en los dos inventarios, y sobre todo las camas más ricas, cuyas descripciones coinciden perfectamente:

Casa del Jardín (Pola de Siero)

[...] una cama de hévano en que dormía dicho señor marqués con sus barandillas en el mismo quarto, una cama blanca dorada y un dosel a la cavezera de ella en el quarto de junto al prado, una cama de hévano con sus colgaduras de damas- 
co encarnado guarnecida en seda y [...] sin dosel a la cavezera de lo mismo y laminitas pendientes de la otra cama doradas.

[...] una cama que está en la galería en el quarto más un [...] de la capilla que es en él encarnada contadas sus colgaduras de damasco verde la guarnición con su dosel de lo mismo [...] (ACHV 1692).

Casa de la Rúa (Oviedo)

[...] Y de allí se passó al dormitorio que corresponde a dicho quarto de estrado, que es él en donde fallezió la dicha Marquesa, en donde se halló una cama de granadillo bronceada con su colgadura de damasco de seda encarnado, un jergón, quatro colchones, dos sávanas, quatro almoadas con su lana y una colcha de lienzo [...].

Y de allí se pasó al quarto que llaman de sorriba, en donde se encontró una cama de madera encarnada con su colgadura de damasco verde y rodapiés de lo mismo, con tres colchones, dos sávanas, quatro almoadas con su lana y una colcha de damasco encarnada [...] (AHPA 1717bis).

Que sepamos, todos los bienes descritos en estos inventarios se destruyeron o dispersaron, por haber pasado probablemente la mayor parte de ellos a la Casa de la Rúa de Oviedo. Esta fue saqueada en reiteradas ocasiones durante la Guerra de Independencia, asunto que demostró perfectamente el padre Patac sobre la base de documentos conservados en el archivo de la propia casa:

(Escrita desde el 16 de mayo hasta el 2 de julio de 1809)

Excmos. Señores Marqueses de Santa Cruz:

$[\ldots]$

Cuando ya se marcharon los enemigos [los franceses] de la capital, me vine a ella y en las casas de V.E., mía y de otros muchos, se hallaron todos los muebles y efectos robados en la mayor parte y los que no hechos pedazos inservibles, sin dejar vidriera, cerradura, puerta ni ventana que no padeciese la misma suerte y lo propio algunos tabiques y paredes, en lo cual me sobraron también los malos y desafectos paisanos, que en esta clase de robos se distinguieron poco a los enemigos, con la diferencia de que éstos se tiraban a la plata, alhajas y ropas finas y los otros a todo esto y a los asientos y muebles, caminando de acuerdo los de las dos casas en destrozo y daños.

[...] En la Casa de la Rúa estoy reparando sus puertas, ventanas y peslleras [cerraduras], tapiando de nuevo la comunicación de la huerta a la casa de la viuda, que abrieron los enemigos para servirse más fácilmente de las dos, poniendo en el posible aseo los efectos y papeles destrozados que han dejado, para su seguridad, hasta que V.E. diga el destino y si se ha de reparar de las demás quiebras 
de puertas, ventanas y peslleras interiores, algunos trozos de pared y tabiques por intención depravada, no contando de 4 a 6 vidrieras sin lesión, pues todas las demás las han quebrantado, habiendo otras urgencias a que acudir y de mayor apunto, aunque por otro lado, si se trata de arrendar, siempre sería preciso repararla de lo puramente necesario (Patac 1980: 57-60).

Oviedo y julio 16 de 1809

Excmo. Sr. Marqués de Santa Cruz

[..] Los enemigos, he dicho en mi anterior, habían robado parte de los efectos que habían quedado en la Casa de la Rúa y hecho pedazos otros más, como sucedió a varios. Los espejos de cuerpo entero padecieron esta suerte, lo mismo un cajón de Talavera o china, vidrieras, algunos de los catres, baúles, mesitas y otras cosas, dejando lo inservible; sólo se halló sin lesión la cama de V.E., sofá, sillas finas con la cubierta de tafetán, que recogí de la Universidad, las otras de pajas, algunas mesas de las grandes y ordinarias, pues las otras dos chiquitas han sido también destrozadas, y algún otro mueble, sobre los cuales y su destino me dirá V.E. qué he de hacer.

Estoy preparando los papeles que han quedado en un cofre y dejaron desordenados y hechos una inmundicia, algunos de ellos. Según los que he visto alguna vez, no advierto en el volumen de lo que ocupaban en el baúl, puedan faltar algo de consideración, en medio que hasta ahora no puedo asegurar cuántos y cuáles sean los extraviados o no. En la tarde del jueves antecedente, al día en que entró el enemigo, he dicho a D. Antonio formase un cajón para el resguardo de papeles; el dará razón de si se hizo o no, en donde quedaron, así fueron a Gijón con el demás ajuar.

La criada de cocina y Gertrudis, estando aquí los franceses pudieron recoger de la casa algunos efectos, como calderas y algún otro que llevaron a la Ribera, en donde existen, habiendo dicho a Trelles me pase una lista de ellos. Estas furias de los abismos han hecho en el pueblo tal destrozo y revoltijo de efectos, pasándolos de unas casas a otras que son incalculables los daños causados a los naturales e importan millones de reales.

Ignorando el paradero del coche, lo pregunté a Cifuentes y en duda me dice le parecía haberle visto en la casa del Marqués de S. Esteban, pero promete darme razón más fija. Vea V.E. que es lo que quiere que se haga con él (Patac 1980: 62-63).

La casa de Pola de Siero se vendió por parte de los descendientes de don Sebastián en la década de los 90 del siglo xx al Ayuntamiento de Siero, mientras que la Casa de la Rúa, aunque permanece en la actualidad en manos de los marqueses de Santa Cruz de Marcenado, no contiene ningún mueble anterior al siglo Xx.

Por otra parte, los documentos estudiados representan un vivo retrato de la vida cotidiana de la nobleza asturiana, a caballo entre los siglos XVII y 
XVIII, y pueden compararse con la de otras familias, como por ejemplo los Miranda, emparentados directamente con los de la Rúa. De los Miranda, se conserva en el archivo del Real Instituto de Estudios Asturianos (Oviedo) un inventario de 1719 (prácticamente contemporáneo, por tanto, del inventario de los bienes de doña Jacinta Antonia) (RIDEA 1719, doc. 3), que incluye los bienes que quedaron tras la muerte del Marqués de Valdecarzana en sus casas de Grado, Muros de Nalón, Villanueva, Teverga y Oviedo. Los bienes que quedaron en la casa de Oviedo, por ejemplo, presentan claras similitudes con los de la Casa de la Rúa y los de la Casa del Jardín. Aparecen en el inventario referencias a las piezas de estrado, a una colección de pintura formada por 36 cuadros, así como bufetes, escaparates con niños Jesús de cera, mesas, baúles, etc. Llaman la atención, sobre todo, las referencias a "dos coches enteramente compuestos, uno de verano y otro de ybierno", a "la mesa cubierta de paño, tres bolas y algunos tacos, rodeado de bancos y dos mesitas" y a "dos silleteras de madera, y en una la silla de manos de raso alto con sus arcos". Otros inventarios de casas nobles asturianas, por ejemplo el palacio de Toreno en Cangas de Narcea, mencionan una alfombra de Flandes, un reloj de campana de bronce y caja de nogal y cuatro escaparates de concha guarnecidos de bronce (Díaz Álvarez 2007).

\section{BIBLIOGRAFÍA CITADA}

Abol, M. de 1986. "La familia "de la Concha": el mayorazgo en la Asturias del Antiguo Régimen", en Liber amicorum profesor don Ignacio de la Concha: 21-50. Oviedo: Universidad de Oviedo.

Bennassar, B. 1982. "Los inventarios post-mortem y la historia de las mentalidades", en Actas del II Coloquio de metodología histórica aplicada. La documentación notarial y la historia. Vol. 2: 139-146. Santiago de Compostela: Universidad de Santiago de Compostela.

Burke, M. B. y P. Cherry 1997. Collections of paintings in Madrid, 1601-1755. Los Ángeles: Provenance Index of the Getty Information Institute.

Cadenas y Vicent, V. 1991. Caballeros de la Orden de Alcántara que efectuaron sus pruebas de ingreso durante el siglo XVIII. Tomo 1. Madrid: Instituto Salazar y Castro.

Díaz Álvarez, J. 2002. "Aproximación al patrimonio rústico de Sebastián Vigil de Quiñones", en F. J. Aranda Pérez (ed.), El mundo rural en la España moderna: 435451. Ciudad Real: Universidad de Castilla-La Mancha.

Díaz Álvarez, J. 2006. Ascenso de una casa asturiana: los Vigil de Quiñones, Marqueses de Santa Cruz de Marcenado. Oviedo: Real Instituto de Estudios Asturianos.

Díaz Álvarez, J. 2007. "La residencia del grupo nobiliario asturiano en el siglo XVIII: arquitectura, interiores, decoración”, en F. Núñez Roldán (ed.), Ocio y vida cotidiana en el mundo hispánico en la Edad Moderna: 199-210. Sevilla: Universidad de Sevilla.

Patac de las Traviesas, J. M. 1980. La Guerra de Independencia en Asturias en los documentos del archivo del Marqués de Santa Cruz de Marcenado. Oviedo: Real Instituto de Estudios Asturianos. 
Ramón-Laca, L. y S. Ríos 2008. "La Casa de la Rúa de Oviedo: hipótesis antes de su restauración", en Actas del Congreso Internacional AREPA 2008. Valladolid: Junta de Comunidades de Castilla y León.

\section{FUENTES DOCUMENTALES}

ACHV (1692). Archivo de la Chancillería de Valladolid, Registro de Ejecutorias, caja 312412.

Calatrava (1680). Expediente de solicitud del hábito por don Joaquín Zapata y Mendoza Guevara y Zapata, Archivo Histórico Nacional, OM, Calatrava, exp. 2869.

Calatrava (1669). Expediente de solicitud del hábito por don Sebastián Vigil de la Rúa, Archivo Histórico Nacional, OM, Calatrava, exp. 2795, Madrid.

AHPA (1717). Testamento y tres codicilos de la II Marquesa de Santa Cruz de Marcenado, doña Jacinta Antonia de Vigil y Bernardo de la Rúa, Oviedo, 6 de junio de 1717, Archivo Histórico de Protocolos de Asturias, protocolo notarial 7595.

AHPA (1717 bis). Ymbentario de los vienes que quedaron por muerte de la señora doña Jazinta Antonia Vigil de la Rúa, Marquesa que fue de Santa Cruz de Marcenado, Oviedo, 8 de julio de 1717, Archivo Histórico de Protocolos de Asturias, protocolo notarial 7596.

RIDEA (1719). Ymbentario que se hizo en el año de 1719 de las alaxas que el Marqués de Baldecarzana dejó en sus casas de la villa de Grado, Muros, Villanueva, Teberga y la desta ziudad de Oviedo que llaman de Miranda, y en las del campo de dicha ziudad, Archivo del Real Instituto de Estudios Asturianos, Valdecarzana 13/54.

\section{ANEXO}

\section{Documentos de archivo}

Doc. 1: Inventario de los bienes que quedaron en la Casa del Jardín (Siero) a la muerte del I Marqués en 1692 (ACHV 1692)

"[...] Ante mí, Andrés Vijil Bernardo, en la villa de Siero el día mes y año arriba dichos, nos, teniendo en mi presencia a la señora doña María Josepha de Ribas, biuda que quedó de dicho Señor Marqués, que la ley y en el auto de arriba en persona, que lo oió y entendió y aviendo jurado según se ve, que fue dando dicho ymbentario en la forma siguiente:

Primeramente, una dozena de sillas de felpa encarnada con clavazón dorada que dixo dicha Señora aver traído de Madrid quando se casó con dicha Señor Marqués y también quatro taburetes de felpa hermanos de dichas sillas, que también dizen vinieron de Madrid. Más catorze sillas de baqueta de moscobia viejas, más una frasquera de nueve frascos, más una piel de oso, más un quadro de Santa Rosa de Viterbo,más otro quadro de San Sebastián, más otro quadro de David, más otro quadro de Nuestra Señora, más otro quadro de Nuestra Señora de la Conzepzión, más otro quadro de San Ignacio, más otro quadro de la Magdalena, más un quadro del retrato de dicho Señor Marqués, otro 
quadro de Nuestra Señora de los Siete Dolores, otro quadro del glorioso San Joseph,otro quadro de la Santa Marina, otro quadro del señor San Onofre, otro de Nuestra Señora de la Conzepzión ya biexo, otro de Santa Isavel Reyna de Portugal, otro de un Santo Xristo y el glorioso San Francisco,otro de la Santa Chatalina, otro del señor San Juan con el cordero, otro del señor San Jerónimo, otro de Santa Rosa del Perú, otro del Santo Rei don Fernando con las llaves de Sevilla, otro del señor San Antonio, otro de la Magdalena difunta, otro de San Diego de Alcalá, otro en que está pintado un tigre, otro con la pintura de un león, otro frutero, otro de la pintura de un lobo, otro de la Magdalena combertida, otro de un santo Cristo, otro del Ángel de la Guarda, otro de la Encarnazión, otro de San Francisco ya biexo, otro de Santo Domingo soriano, otro también del Ángel de la Guarda, otro frutero, otro del señor San Sebastián, una estampa de papel, otro quadro de la tentación de San Francisco, otro del zirujano con la jeringa, otro frutero biexo, otro quadro de Nuestro Señor que le enarbolaron en la cruz dize dichas pinturas la Marquesa que binieron de Madrid. Uno de Nuestra Señora de la Encarnazión con marcos dorados que dize dicha Señora binieron de Madrid, otro de Nuestra Señora de la Soledad, dos espejos grandes que dize dicha Señora binieron de Madrid, otro quadro de las Angustias, otro quadro de un tygre, otros dos espejos pequeños dorados, un San Lorenzo pequeño de marco dorado, otro relicario pequeño viejo, una lámina de san Elifonso de piedra de ágata que dize dicha Señora bino de Madrid, otra lámina de Nuestra Señora de la Encarnazión, un espejo que también dize bino de Madrid, más una lámina de bronze de San Joseph y el Niño con unas piedra que también dize bino de Madrid, otro relicario negro que también dize bino de Madrid, otra lámina grande de Nuestra Señora de bronze con quatro santos que también dize bino de Madrid, más otra lámina con marco negro de una ymajen que también dize bino de Madrid, mas otra lámina ${ }^{f} d e$ otra [...] dize bino de Madrid, más otra lámina grande con su figura que también dize vino de Madrid, otra lámina dorada de Nuestra Señora y el niño Jesús que también dize vino de Madrid, otra lámina también dize que vino de Madrid, otra lámina de San Reymundo, otra lámina del Santo Cristo de Burgos que también dizen bino de Madrid, otro parezido pequeñito que también dize bino de Madrid, más una mesa con dos tiradores seis pies de tres varas de largo o poco más o menos, la mesa de los trucos con sus bolas y tacos, otros dos quadros yguales con marcos dorados de San Pedro y San Pablo que también dize la Señora binieron de Madrid, otro quadro grande algo dorado con el Ángel de la Guarda en lo alto, otro quadro del mismo tamaño de San Pedro con sus llaves, otro quadro más pequeño de la galería de la Virgen del Rosario, otro quadro grande de la Virjen en contemplación que también dize vino de Madrid, otro quadro de las lágrimas de San Pedro de gran tamaño algo dorado, otro quadro de medio canpo de Nuestra Señora que está en duda dicha Señora si vino de Madrid, otro quadro del santo Ángel de la Guarda con su letrera, otro quadro de Nuestra Señora de la Asunzión marco todo dorado que dize dicha Señora vino de Madrid, otro quadro de Santa Clara sin marco, otro quadro de Santo Domingo con otra himájenes, otro quadro de San Juan, una silla de manos, un vufete de quatro pies de vara de ancho y bara y media de largo con su tirador, un banco de respaldo exerido de clavos de concha, dos escritorios de granadillo, el uno con nuebe gavetas y [...], el otro tapados con sus baquetas, una mesita de quatro pies embutida, una mesa de nogal nueba de seis pies de tres varas de largo poco más o menos y casi otra de ancho, otra mesa de seis pies de vara en ancho y quatro de largo, otra mesa de encaje de tres piezas y seis pies vara de ancho seis pies de largo poco más o menos, otra mesa de zinco pies 
en una de zinco quartas de ancho y quatro [...] y más de dos baras de largo, otra mesa de la misma echura, tres vancos de respaldo de tornillos de buen largo, otro vanco de respaldo con clavos de concha, un cajón a la subida de la escalera, otro cajón como se entra a la cozina con dos apartados, y otro cajón en riba del otro cajón en el mismo sitio de sus dos puertas, y arriva su alazena con reja, otro vanco de respaldo en las cozinas con clavos de concha, mesita vieja pequeña en la cozina, otro banco sin respaldo en dicha cozina, una arquilla pequeñita nueba que ará zinco [...], otra mesita pequeña de quatro pies y bara de largo, otra arca en dicha cozina con zerradura y llave, otras [...] enzima de una otra en dicha cozina que la una ará quatro anegadas y la otra tres y la otra dos poco más o menos, y en el corredor un cajón viejo de dos puertas, una harqueta enbutida que hará [...], un baúl viejo de mediano tamaño, un cofre claveteado de mediano tamaño con sus dos zerraduras. Y en el quarto de las chimineas un escaparate grande nuebo con sus armas de la cassa de Vijil que sirve para la plata y vidrios con su escalera, un baúl biejo con sus dos zerraduras de mediano tamaño, otro vaúl también biejo con sus tres zerraduras, otro baúl negro de granadillo listas blancas con su zerradura, dos arcas de vuen tamaño de dos zerraduras cada una cubiertas con baqueta y llaves todas de clavos de vronze, otro banco de respaldo grande con clavos de concha, otro banco de respaldo de tornillo, una muleta pequeña de cama enbutida de [...] con su caja en [...] de otras y otras dos arcas que ará cada una seis o siete anegadas, otras dos que arán cada una quatro ... poco más o menos, otra más pequeña que ará dos anegadas y media poco más o menos, y todas con zerraduras y [...] otro baúl biejo en el quarto berde de mediano tamaño con una zerradura, y en el mismo quarto una cama berde, una frasquera vieja sin frascos en el quarto blanco, una cama de hévano en que dormía dicho señor marqués con sus barandillas en el mismo quarto, una cama blanca dorada y un dosel a la cavezera de ella en el quarto de junto al prado, una cama de hévano con sus colgaduras de damasco encarnado guarnecida en seda y [...] sin dosel a la cavezera de lo mismo y laminitas pendientes de la otra cama doradas, en el quarto que llaman de la sala dos camas de madera con cordel, más en el quarto de las chimineas un bufete de quatro pies con su cajón más en [...] otro bufete de quatro pies un tirador en el quarto primero de la galería, otra cama de madera con tablas en el quarto de [...] otra cama de madera sus tornillos [...] más un arca con dos zerraduras larga y vieja [...], un baúl biejo, otro mayor, otro claveteado con clavos de bronze y con zerraduras llave [...] de las cántaras, otro baúl biejo con su zerradura y es ta declaración que dos baúles que ban inventariados en este inbentario por esta erenzia no le son de que estavan en la Pola ha poco, que son de Doña Rosa Jertrudis y Doña Serafina Josepha, hijas de dicho Señor Marqués, por havérselos dado el Señor Don Vizente de Ribas, su abuelo paterno y por ser tarde se suspendió el proseguir este ymbentario asta mañana a que fueron juntos el susodicho Thoribio Suárez, abad de Marzenado y don Bernardo Vijil Hebia, vezino deste concejo, de que doy fe y lo firmó dicha Señora Marquesa, la Marquesa, ante mí Andrés Vijil Bernardo.

En la villa de Siero, a veinte y seis días de dicho mes y año prosiguiendo en dicho ynbentario. La dicha Señora Marquesa debajo de dicho juramento quedando por ynbentario las cosas y vienes siguientes: una cama que está en la galería en el quarto más ynmediato de la capilla que es en él, encarnada, contadas sus colgaduras de damasco verde, la guarnición con su dosel de los mismo. Más se pone por ynbentario por averse allado en el quarto llamado de la torre lo siguiente: una mesa de nogal de vara 
y media poco más o menos y tres quartas de ancho con sus cajones de quatro pies y su zerradura, más otra arca con su zerradura que ará tres anegadas de zevada antes más que menos esta, dicha Señora dize las tenía dado [...] dicho Señor Marqués al lizenciado don Thoribio Suárez tenía su capellán para [...] sus alajas, más otra arca en dicho quarto que ará zinco o seis anegadas de zevada con llave y zerradura, más un banco de respaldo, una cama de nogal con sus cordeles, un bufetico pequeño de vara de largo y dos terzias de ancho de quatro pies torniado más dos sillas de baqueta de moscobia además de las referidas en este ynbentario [...] que se alló en dicho quarto lo de los herederos del lizenziado Don [...] Miranda, abad que fue de Santa Cruz de Marzenado, que residía en dicho quarto y por ser así notorio no se pone por ynbentario, más otra arca grande en el portal desta casa con su llave y zerradura que ará diez anegadas de zevada poco más o menos, un bancón largo en el [...] que pasa al jardín de nuebe a diez baras de largo y media de ancho antes más que menos, más en el quarto [...] a la puerta de la calle de la mano sinistra como se entra una cama de madera tallada de tabla [...]. Ante mí, Andrés Vijil Bernardo, en la villa de Siero a veinte y ocho días de enero de mil seiscientos y noventa y dos. [...] Más una alfonbra turquesa grande que se alló en estas dichas cassas del jardín, dize mi señora la marquesa que dicha alfonbra no es de esta erenzia y por serlo de dicha doña Rosa Jertrudes su hija por habérsela dejado la señora doña francisca de Guerra su abuela como constava del testamento devajo de cuya disposición [...] escribió ante mí en [...] de mil seis zientos y ochenta y zinco, sinado y firmado a lo que pareze de las de Villa Vinaga, escribano del Rey Nuestro Señor $[\ldots] "$.

Doc. 2: Inventario de los bienes que quedaron en la Casa de la Rúa (Oviedo) a la muerte de la II Marquesa en 1717 (AHPA 1717 bis).

"Ymbentario de los vienes que quedaron por muerte de la señora doña Jazinta Antonia Vigil de la Rúa, Marquesa que fue de Santa Cruz de Marcenado (Oviedo, 1717)

hecho por el señor don Juan Bautista Burgalés de Aguilar, alferez maior de las Reales Guardias de Corps, brigadier de los Reales Exércitos de Su Magestad, gobernador político y militar de esta ciudad y Principado

[...] En las casas de la Rúa (8 julio 1717)

[...] Primeramente en la antesala que cae a la calle pública se hallaron dos mesas de madera, la una en seis pies y la otra de quatro, sin ferraduras ni llaves, con sus carpetas, y también quatro vancos de respaldo torneados, y también siete quadros grandes de santas y virtudes, y también otros tres quadros viejos pequeños, y también quatro sillas de vaqueta de moscobia viejas y no otra cosa. Y de allí se paso al otro quarto del estrado que sigue a dicha antesala y cae a la calle, en donde se encontraron dos escriptorios de tortuga finos con sus mesilla, y en ambos las llaves de sus navetas, que aviéndose visto y reconozido estas en ellas no se halló cosa alguna, y también otra mesilla con su carpeta de damasco encarnado, y sobre ella un niño Jesús en un escaparate con su vidriera, y también tres quadros largos, sus pinturas paýses con sus marcos dorados, 
otros tres quadros grandes sin marcos de pintura fina, más otro quadrito pequeño viejo, y también seis silla de vaqueta, una estera fina con ochos, almoadas de damasco encarnado uno y otro estrado, y también quatro cortinas de morlés en las puertas y ventanas de dicho quarto, una mesa de madera de nogal embutido y de estrado, y en el no se halló otra cosa. Y de allí se pasó al pasadizo y primer quarto de el correspondiente a dicho estrado, en donde se halló un escriptorio antiguo viejo de madera y para el reconozimiento de que en sí conservaba dicho señor gobernador para con la llave que paraba en su poder, pasó a abrir la dicha arca, de la qual sacó las que dentro de ella estaban, dejando esta pestillada y zerrada [...] se halló el dicho scriptorio antiguo y haviendo visto y reconozidos sus navetas, en ellas no se halló otra cosa que unos mazos de carta viejas y antiguas escriptas por diferentes personas a don Juan Bernardo de la Rua, dueño y poseedor que fue de estas dichas casas, que por no ser de utilidad alguna, dicho señor Governador hizo se quedasen en dichas navetas sin que de ellas se hiziese memoria, dejando dicho scriptorio zerrado con sus llaves, las quales dijeron paraban en poder de doña María Francisca Castro, vez de doncella en estas dichas casas, a quien dicho señor Governador hizo llamar para que abriese dicho vaúl y arca como con efecto lo hizo y, aviéndose reconozido lo que en sí enzerraban, se hallaron los vestidos y ropas del cuerpo de la susodicha, quien bolbió a zerrar y recoger dichas llaves, y también una cama de madera pintada de encarnado con su jergón, colcha blanca, y también otros dos colchones, dos cobertores, dos sávanas y dos almoadas con su lana, la una de texer y la otra de lienzo, y también diez almoadas de damasco negro de estrado, y también una silla de baqueta vieja, y en dicho primer quarto del pasadizo no se halló otra cosa. Y de allí se pasó al segundo quarto del mismo pasadizo, en donde se halló un scriptorio viejo de tortuga, y sus navetas abiertas que aviéndose rejistrado en ella no se halló cosa alguna, y también otro scriptorio de madera grande zerrado con su llave que haviéndose abierto en él no se halló cosa alguna, y también otra arqueta pequeña y larga de madera con zerradura y llave que haviéndose abierta en ella no se halló nada, y también otro escriptorio de madera negro sin mesilla, con su zerradura y llave, que aviéndose abierto en él no se halló cosa alguna, y también una cama de campo de madera de nogal enbutida con su jergón, dos colchones, un cobertor, dos sávanas, dos almoadas con su lana y colcha blanca de lienzo, y también otra cama de madera vieja sin testera, con su jergón y una colcha blanca, y en dicho quarto no se halló otra cosa. Y de allí se paso al quarto del estrado, que cae al jardín, en donde se hallaron quatro grandes pinturas finas antiguas, otros zinco quadros pequeños, una estera fina clavada en la paré, dos espejos grandes de vestir, un brasero bronceado con su copa de metal, y en dicho quarto no se halló otra cosa alguna. Y de allí se passó al dormitorio que corresponde a dicho quarto de estrado, que es él en donde fallezió la dicha Marquesa, en donde se halló una cama de granadillo bronceada con su colgadura de damasco de seda encarnado, un jergón, quatro colchones, dos sávanas, quatro almoadas con su lana y una colcha de lienzo, y dentro de dicho dormitorio se halló la arca de cuia llave se hizo entrego a dicho Señor Governador, la que bolbió a mandar abrir con ella, y aviéndose rejistrado en ella se encontraron asta dozena y media de bollos de chocolate de a libra y por labrar, como cosa de media arroba poco más o menos, y diferentes papeles, cuio reconozimiento suspendió por aora su señoria y dicha arca la bolbió a zerrar con su llave, y también una arca y un vaul grande con sus zerraduras llaves, que haviéndose avierto y rejistrado solo se hallaron diferentes papeles en atados, y algunos libros manuscriptos enpergaminados, cuio reconozimiento de lo que ellos con- 
tienen dicho señor gobernador lo suspendió por aora asta los poner en su lugar y con toda distinzión y claridad, dejando zerrado con sus llaves dicha arca y baul, y también otra arca mediana y un baulillo de camino con sus cerraduras llaves que aviéndose avierto en ellas no se halló cosa alguna, y en dho dormitorio no se halló más. Y de allí se pasó a la sala grande que cae al jardín, en donde se hallaron nuebe quadros grandes, sin marcos, una mesa grande con dos tiradores zerraduras y sin llaves, dentro de los quales no se halló cosa alguna, y dicha mesa cubierta con su carpeta, dos vancos de madera de respaldo, quatro cortinas de estameña verdes, y en dicha sala no se halló otra cosa. Y de allí se pasó a la antesala de la sala referida, en donde se halló una mesa de madera de seis pies, una arca de madera con su zerradura y llave que aviéndose abierto en ella no se halló cosa alguna, otro cajón de madera donde se entra el servizio de mesa, dentro del qual se halló la plata siguiente: primeramente un taller sobredorado con su azeitera, vinagera, pimentero, azucarero y salero, una salvilla con quatro vasos de encaje, una fuente del recado de mesa sobredorada, un jarro asimismo dorado, una palangana, un bernegal con su plato hechura de salvilla, otros quatro vassos, ocho tenedores, onze cucharas y entre ella la una partida, quatro candeleros, los dos grandes y los otros dos pequeños, otros quatro tenedores, un cáliz con su patena, todo de plata, un biombo viejo, y en dicha antesala no se halló otra cosa, y toda la referida plata susodicha el señor governador mediante el usso de ella la encargó la tubiese con toda guarda y custodia a Juan de Estevano, criado que corre con ella, quien dijo lo haría con toda fidelidad. Y de allí se pasó al cuarto del corredor que está a espaldas de la sala, y que corresponde al patio de dichas casas, en donde se halló una cama de granadillo con su jergón, dos colchones, dos sávanas, dos almoadas, un cobertor y una colcha de seda color pajizo, ya usada, y también otros dos colchones, dos sávanas, dos almoadas y una carpeta, una mesilla de madera de nogal, una silla y un taburete de vaqueta de moscovia viejo y un quadro pequeño y viejo, y en dicho quarto no se halló otra cosa. Y de allí dicho señor governador pasó a otros dos quartos nuebos que corresponden al mismo patio, y en el primero se halló una cama de nogal con su jergón, colchón, cobertor, dos sávanas y dos almoadas. Y en el segundo otro cama de nogal con su jergón, colchón, cobertor, dos sávanas y dos almoadas con su lana y, en este mismo quarto, otro colchón con su cobertor, una colcha y dos sávanas viejas y gruesas, y no otra cosa. Y de allí se pasó al quarto que llaman de sorriba, en donde se encontró una cama de madera encarnada con su colgadura de damasco verde y rodapiés de lo mismo, con tres colchones, dos sávanas, quatro almoadas con su lana y una colcha de damasco encarnada, una mesilla con su carpeta, tres cortinas de damasco encarnadas, una mesilla con su carpeta, tres cortinas de las de tafetán verde, y en dicho quarto no se halló otra cosa. Y de allí se pasó al pasadizo de él, que se halla junto a la escalera de la torre, en donde se hallaron tres arcas, la una grande y las dos medianas con sus zerraduras y llaves que aviéndose avierto se halló asta ocho fanegas de escanda, las quales se bolbieron a zerrar con su llave, y en dicho sitio no se halló otra cosa. Y de allí se pasó al quarto grande de la cozina y en un dormitorio se hallaron dos camas de madera ordinaria y cada una con su jergón, colchón, dos sávanas gruesas, dos mantas, un cobertor, y en la una una colcha vieja de lienzo y en dicha cozina dos arcas viejas, dos mesas y un cajón viejo, todo sin llaves, y aviéndose abierto en lo uno y otro no se halló nada, tres ferradas con su canjilón, siete calderas grandes y pequeñas, las quatro de cobre y las tres de azofre, una almirez con su mano, un pote de fierro, ocho cazos los zinco de fierro, dos de azofre y uno de cobre, dos asadores y un cavallete de fierro, dos chocolateras, zinco 
docenas de platos de peltre con seis fuentes de lo mismo, y en dicha cozina no se halló otra cosa. Y de allí se pasó al corredor que corresponde al jardín, en donde se halló un cajón a modo de scriptorio con su zerradura y llave, que aviéndose avierto en él no se halló cosa alguna, y faltoso de navetas, y en dicho corredor no se halló otra cosa. Y de allí se passó al oratorio que se halla a un lado del mismo corredor, en donde se halló formado un altar, con su ara, cubierta con una sábana, la efixie de un santo Christo de plata, de una quarta de largo y en lo superior de dicho altar un quadro con la ymajen de San Sevastián y a los lados algunas láminas, misal y corporales, casulla, alba y más [...] para se bestir qualquiera sacerdote y poder dezir misa y no otra cosa. Y también se pone asimismo por ymbentario un furlón con dos mulas de coche, sillas, frenos y más peltrechos para un transporte y en dicha casa no se halló otra cosa alguna más que tan solo una esclava negra llamada Theresa de Jesús, la qual con todos los vienes que ban expresados dicho sñor governador dejó en ella encargado lo uno y lo otro a dicho señor Vizconde, quien le hallara no a le tener a derecho, y entregarlo siempre que por su señoría se le mande, y las llaves de dichos papeles y arcas, en donde se han en poder de su señoría dicho señor governador para proseguir dicho ymbentario quando y como convenga, y para que conste lo mando poner por diligencia, y mismo junto con dicho Vizconde de Puerto, de que doi fee".

Doc. 3: Inventario de los bienes que quedaron en la Casa de Oviedo a la muerte del Marqués de Valdecarzana en 1719 (RIDEA 1719)

"En la Casa de Miranda de esta ciudad de Oviedo:

Primeramente en el rezivimiento de las piezas de estrado, quatro fruteros apaisados de bara y media de largo

Ytt. siete retratos de querpo entero de diferentes señores de la Casa de Miranda

Ytt. un bufetillo de nogal con sus traveseros de hierro

\section{Pieza primera del estrado:}

Ytt. dos países grandes, con diferentes figuras

Ytt. dos fruteros más pequeños

Ytt. un quadro de San Sebastián de cuerpo entero y sin marco

Ytt. un Christo echado

Ytt. un San Lorenzo

Ytt. un San Bizente grande con su marco

Ytt. un quadro apaisado con su marco de la efixie de Jesucristo pidiéndole San Pedro

Ytt. un quadro de la resurrezión con su marco

Ytt. un quadro de San Francisco de medio cuerpo

Ytt. otro del templo de Salomón

Ytt. otro de Nuestra Señora y el Padre Eterno

Ytt. otro del Prendimiento de San Andrés

Ytt. otro de San Juan en el desierto 
Ytt. dos escaparates con sus Niños de zera

Ytt. dos bufetillos pequeños, el uno de nogal y el otro de cañamazo

Ytt. quatro cántaros de barro fino

Ytt. un escaparate con sus marcos dorados

Ytt. un friso en dicha sala

\section{Pieza segunda:}

Ytt. un quadro grande de San Andrés sin marco

Ytt. otro de la misma efixie de arriba y tamaño

Ytt. otro de Nuestra Señora de la Asunzión con su marco de vara y quarto de largo

Ytt. un espexo de armar con su marco de ébano

Ytt. un quadro de San Diego sin marco

Ytt. dos de San Pedro y Santo Domingo orlados de flores

Ytt. dos países grandes de montería

Ytt. un quadro de San Pedro Regalado con su marco orlado de flores

Ytt. otro grande de Nuestra Señora y San Ildefonso

Ytt. dos escaparates negros con sus bufeticos y fundas de rasetta

Ytt. tres frisos

\section{Pieza tercera:}

Un bufetillo de nogal con sus barrotes de hierro

Ytt. otro de lo mismo con barrotes de madera

Ytt. un marco de espexo dorado

Ytt. un baúl forrado en piel de buey

Una arca mediana de nogal

Otra de castaño

Más otra de pino

\section{Quarto de las criadas:}

Una arca mediana de nogal

Otras dos grandes

Ytt. unas lazenillas de madera

Más dos sillitas de madera vieja [...]

\section{Cochera:}

Dos coches enteramente compuestos, uno de verano y otro de ybierno

Una rueda del juego delantero

Quatros vidros medianos hordinarios

\section{Bodega:}

Tres pipas y un duerno de hazer sanmartín 


\section{Quarto de los trucos:}

La mesa cubierta de paño, tres bolas y algunos tacos, rodeado de bancos y dos mesitas

Patio:

Quatro arcas de echar escanda

Dos silleteras de madera, y en una la silla de manos de raso alto con sus arcos".

Fecha de recepción: 15 de junio de 2009

Fecha de aceptación: 22 de diciembre de 2009 